\title{
Development and Validation of a Maternal Overprotection Scale for Young Children
}

\author{
Young Sun Chung ${ }^{1}$, Kyung Ja Park ${ }^{2}$ \\ Assistant Professor, Department of Child and Youth Welfare, Pyeongtaek University, Pyeongtaek, Korea ${ }^{1}$ \\ Professor, Department of Child and Family Studies, Yonsei University, Seoul, Korea ${ }^{2}$
유아기 자녀를 둔 어머니의 과보호 양육척도 개발과 타당화 연구
정영선 ${ }^{1}$, 박경자 ${ }^{2}$
평택대학교 아동청소년교육상담학과 조교수 ${ }^{1}$, 연세대학교 아동·가족학과 교수 ${ }^{2}$

\begin{abstract}
Objectives: This study aimed to develop and validate the Maternal Overprotection Scale to measure the degree of maternal overprotective behaviors in child-rearing.

Methods: There were two parts in this study. In Study 1, the items and scale development was conducted and in Study 2, the scale evaluation was conducted. In Study 1, the sample consisted of 262 mothers with young children aged from five to six years. Mothers rated themselves on the degree of their overprotecting behaviors carried toward their children. The scale initially comprised 45 items, and it ended up with 18 items based on exploratory factor analysis and exploratory structural equation modeling. In Study 2, the data of additional 197 mothers who responded to these items were analyzed by means of confirmatory factor analysis and correlation analysis.

Results: In Study 1, the exploratory factor analysis and exploratory structural equation modeling of the scale identified three sub-scale factors: Intrusive Control (eight items), Permissive Indulgence (four items), and Anxious Protection (six items). In Study 2, the Cronbach's $\alpha$ values ranged from .70 to .85, showing appropriate levels of internal consistency. The cross-validation was established using different samples. The concurrent validity was confirmed by the association with a maternal parenting attitude measured by the Parenting Dimensions Questionnaire (PBDQ).

Conclusion: The Maternal Overprotection Scale reliably and accurately measured degrees of overprotective maternal parenting with young children. This scale can be used as a tool for estimating individual differences in mothers' overprotection for their young children, as well as correlations with other aspects of development.
\end{abstract}

Keywords: overprotection, young children, scale development, validation

\section{Introduction}

핵가족화, 여성의 사회진출, 늦어지는 결혼과 출산 시기 등으 로 인해 자녀의 수가 감소하면서 1-2명의 자녀를 둔 가구 비율 은 2019년 전체의 약 $90 \%$ 를 차지하여, 1970 년 23\%에 비하여 급증하였다(Statistics Korea, 2019a). 과거에 비교해 자녀의 수

Corresponding Author: Kyung Ja Park, Professor, Department of Child \& Family Studies, Yonsei University, 50 Yonsei-ro Seodaemun-gu, Seoul, Korea

E-mail: kjpark@yonsei.ac.kr
가 감소하였음에도 불구하고 부모들은 양육의 부담이 줄어들 지 않고 오히려 더 커졌다고 느끼고 있다. 이런 현상은 부모가 자녀를 위해 무엇까지 해주어야 하는지에 대한 기대 수준이 높아지고, 사회적 시계(social clock)가 점점 느려져 자녀들의 경제적 독립이 늦어지면서 부모가 개입할 수 있는 여지가 많 아진 것과 관계가 있을 수 있다. 최근 자녀의 삶에 적극적으로

(C)The Korean Association of Child Studies

This is an Open Access article distributed under the terms of the Creative Commons Attribution Non-Commercial License (http:// creativecommons.org/licenses/by-nc/4.0) which permits unrestricted noncommercial use, distribution, and reproduction in any medium, provided the original work is properly cited. 
개입하며, 자녀의 자율성과 독립성을 저해하고 의존성을 높이 는 과보호적인 양육을 하는 부모가 늘어나면서 이에 대한 사 회적, 학문적 관심이 높아지고 있다.

과보호 양육의 양상은 자녀의 연령에 따라 달라질 수 있다. 또한 과보호 양육은 자녀의 어느 시기에만 나타날 수도 있지 만 부모가 자녀를 양육하는 특성으로 오랜 기간 지속될 수 있 고, 이러한 과보호 양육의 영향은 누적 효과와 지연 효과를 통 해 자녀가 성장하면서 더 잘 드러날 수 있게 된다. 본 연구에서 는 유아기에 초점을 맞추어 유아기 자녀를 둔 부모의 과보호 양육의 특성을 살펴보고자 한다.

과보호 양육은 유아가 자신의 일을 스스로 하는 것과 위 험하지만 도전적인 일을 하는 것을 제한하기 때문에 유아의 자율성과 주도성에 부정적 영향을 미칠 수 있다(McShane \& Hastings, 2009). 유아는 자조능력을 키우면서 유능감과 자율 성을 높이고, 스스로 목표를 달성하거나 문제를 해결함으로 써 주도성을 획득한다. 자녀가 겪을 어려움에 대해 지나치게 걱정하여 자녀의 일상생활에 적극적으로 개입하는 어머니 밑 에서 과보호 양육을 받은 유아는 시행착오를 통해 어려움을 극복할 기회가 부족하여 문제해결에 대한 효능감과 숙달동기 가 낮고(L. Kim, 2017), 문제 상황에서 주도적으로 해결하려 하기보다는 성인에게 지나치게 의존하며(Wood, 2006; Wood, Kiff, Jacobs, Ifekwunigwe, \& Piacentini, 2007), 해결하려는 시도 가 좌절되었을 때 다시 재도전하기보다는 회피하는 반응을 보 였다(Jang, 2016). 부모의 지나친 보호 아래서 자율성과 주도 성을 키우지 못하고 의존적이게 된 유아는 문제 상황에 대한 대처 능력과 자신감이 부족할 수 있다(Kiel, Wagers, \& Luebbe, 2019). 또한 걸음마기에 과보호적 양육태도를 보인 어머니는 이후 유아기와 아동기에도 여전히 자녀를 과보호하는 경향 이 있었으며, 이는 자녀의 높은 불안 수준을 예측하였다(Bayer, Sanson, \& Hemphill, 2006; Kiel \& Buss, 2011; Kiel, Premo, \& Buss, 2016; Laurin, Joussemet, Tremblay, \& Boivin, 2015).

부모의 과보호 양육이 유아의 발달에 부정적인 영향을 미 칠 수 있음에도 불구하고 이에 대한 연구가 충분히 이루어지 지 않고 있으며, 연구 결과를 해석하기에도 몇 가지 제한점이 있다. 가장 주된 이유는 유아 자녀를 둔 부모의 과보호 양육에 대한 정의가 연구마다 일치하지 않고, 측정도 외국에서 개발 된 척도를 주로 사용하여 문화적으로 적절하게 측정되지 않은 부분이 있기 때문이다.

우선 유아기 자녀를 둔 어머니의 과보호 양육이 무엇인지 에 대해 학문적으로 합의된 정의가 없어 연구마다 정의가 다 르게 적용되고 이로 인해 기존의 연구 결과를 비교하는데 어
려움이 있다. 예를 들어, 과보호 양육과 유아 불안 간의 관계에 대한 선행 연구들은(Kiel \& Buss, 2011; Kiel et al., 2016) 과보호 양육을 위험 요인에 자녀가 접근하는 것을 제한하는 통제적 양육의 한 형태로 정의하였지만, I. J. Chung의 연구(2012)에 서는 과보호 양육을 "아이의 일을 대신 해주거나", "내 생활을 포기하고 아이를 돌보는" 허용적 특성을 과보호 양육의 정의 에 포함하였다. 그리고 유아들을 대상으로 과보호 양육을 살 펴본 연구가 많지 않아 유아기 과보호 양육의 측면에 대한 고 찰이 부족하였다. 과보호 양육은 어느 영역에서는 제한적이고 통제적이며, 어느 영역에서는 적절한 수준 이상으로 허용적 이고 반응적인 부분이 혼재하여(Park, 1998; Thomasgard, Metz, Edelbrock, \& Shonkoff, 1995), 기존 양육 연구에서 사용한 개념 적 틀로 과보호 양육을 정의하는 것은 어렵다. 따라서 유아를 대상으로 과보호 양육에 대한 연구를 실시하기 위해서는 발달 적 특성을 고려하여 과보호 양육에 대한 정의를 확립하는 것 이 우선적으로 필요하다.

과보호 양육은 다음과 같은 세 가지 특징을 갖는다. 우선 부 모의 과보호 양육은 자녀에 대해 지나치게 걱정하고 염려하는 양육태도를 포함한다. Levy (1966)와 Parker (1983)는 공통적으 로 과보호 양육이 부모의 불안한 마음에서 시작된다고 보았다 (Thomasgard \& Metz, 1993). 과보호하는 부모는 자녀가 신체적, 심리적인 것을 포함한 모든 측면에서 안전하기를 바라서 지나 치거나 발달적으로 부적절한 수준의 보호를 한다(Thomasgard et al., 1995). 둘째, 과보호하는 부모는 자녀를 보호하기 위해 자 녀의 일에 간섭·침해하고 자녀의 행동과 환경을 발달에 적합 하지 않게 통제한다. 과보호하는 부모는 자녀가 겪는 작은 어 려움에도 개입하여 도와주며(Park, 1998), 성장 단계에 맞지 않 게 자녀가 할 일을 대신해주고(E. Y. Chung \& Chang, 2008), 스 트레스나 위험 상황으로부터 보호하고자 환경을 제한하는 등 발달에 적합하지 않은 간섭과 통제로 자녀의 자율성을 저해하 고 의존성을 높인다(Kiel \& Buss, 2011). 셋째, 과보호하는 부모 는 어느 영역에서는 자녀의 응석을 받아주며 허용적이다. 이 러한 부모는 자녀의 일상을 통제하기도 하지만 동시에 자신 의 일에 책임지게 하지 않는 허용적 태도를 보인다(Park, 1998; Thomasgard et al., 1995). 허용적 과보호를 하는 부모는 자녀와 신체적으로 근접하게 지내고자 하며(Levy, 1966), 자녀가 상처 받을까봐 잘못을 감싸거나 속상한 마음을 적절한 수준 이상으 로 위로하기도 한다(Kiel \& Buss, 2011).

이와 같이 과보호 양육은 걱정으로 인한 보호적 특성과 함 께 침해, 간섭 양육행동을 포함하는 통제적 특성, 그리고 허용 적 특성을 포함한다. 따라서 본 연구는 유아가 부정적 경험을 
하는 것을 걱정하고 보호하여 발달에 적합하지 않게 통제하고 허용하는 양육태도를 과보호 양육으로 정의한다.

다음으로 기존 과보호 양육 연구를 해석하는데 또 다른 제 한점은 유아기 자녀를 둔 어머니의 과보호 양육을 적절하게 측 정하는 도구가 부족하여 국외에서 개발한 과보호 양육 측정 도구를 번역하여 사용한 경우가 많다는 것이다(K. M. Chung \& Yoon, 2015). 유아기 자녀에게 적용할 수 있는 과보호 양육 척도는 Thomasgard 등(1995)이 개발한 부모 보호 척도(Parent Protection Scale [PPS])와 Edwards, Rapee와 Kennedy (2010)가 개 발한 과보호 질문지(Overprotection [OP])가 있다. PPS는 부모 의 자기보고 질문지로 감독(supervision), 분리 문제(separation problems), 의존성(dependence), 통제(control)의 하위요인으로 구성되어 있으나 의존성과 통제 하위요인이 개념적으로 명확 하게 구분되지 않으며, 만 2 세에서 10 세 자녀를 대상으로 하기 때문에 일부 문항들이 유아 연령에 적합하지 않은 제한점이 있 다. OP는 만 3-5세 유아기 자녀를 둔 어머니를 대상으로 한 자 기보고식 과보호 양육척도이지만, 일부 문항들이 한국 문화와 맞지 않는다. 예를 들어, "나는 아이가 나무에 오르는 것을 허 락하지 않는다." 문항은 개인 소유 마당이 없는 아파트나 다세 대 주택에 사는 한국의 주거 문화에 적합하지 않다.

위와 같이 국외 과보호 양육척도의 일부 문항이 문화적으 로 타당하지 않은 이유는 과보호 양육의 정의가 문화에 따라 차이가 있어 동일한 행동이 어느 문화권에서는 과보호 양육 에 해당할 수 있지만 다른 문화권에서는 아닐 수도 있기 때문 이다. 예를 들어, 자율성과 독립성을 중요하게 여기는 미국이 나 유럽의 개인주의 문화에서는 어머니가 노크 없이 방에 들 어가거나 잠을 자고 오는 캠프에 자녀를 보내지 않는 것이 과 보호 양육에 포함되지만(Levy, 1966; Wood, 2006), 한국에서는 이것이 어머니의 과보호 양육을 나타내는 행동이 아닐 수 있 다. 그런데 국외에서 개발한 과보호 양육 척도 대부분이 아이 와 함께 자는 것을 과보호 양육의 주요 문항들로 포함하고 있 다(Wood, 2006). 따라서 이러한 도구로 한국 부모의 과보호 양 육을 측정하면 실제로 과보호를 하지 않는 부모도 높은 점수 를 받게 될 가능성이 높아 연구 결과가 왜곡될 수 있다.

한국의 과보호 양육은 통제적인 동시에 애정과 허용의 수 준이 높은 특징을 갖는다(K. M. Chung \& Yoon, 2015). 자녀의 성취와 성공을 중요하게 여기고(E. Y. Chung \& Chang, 2008), 체면문화로 다른 사람과 자신을 비교하는 한국 부모의 심리적 특성은 어머니 불안의 근원이 되어 과보호 양육의 동기로 작 용한다(Y. H. Kim \& Cohen, 2010). 우리나라에서 유아기 자녀 를 둔 어머니의 과보호 양육을 연구하기 위해서는 양육의 허
용적 측면, 자녀의 성취에 대한 불안과 같은 한국적 과보호 특 성을 반영할 수 있는 연구 도구의 개발이 필요하다.

따라서 본 연구는 기존의 과보호 연구에서 적용된 과보호 양육의 개념이 서로 다르고, 유아기 자녀를 둔 부모를 대상으 로 한 신뢰롭고 타당한 척도가 부족하다는 문제의식을 바탕으 로 유아기 자녀를 둔 어머니의 과보호적인 양육의 정도를 측 정할 수 있는 도구를 개발하고자 한다. 이를 위해 두 개의 연구 를 실시하여, 연구 1 에서는 관련 문헌과 선행 연구들을 참조하 여 과보호 양육이 무엇이며, 어떤 요인들로 구성되어 있는지 를 조사하고 자녀의 연령과 한국 문화에 적합한 문항을 개발 하고자 한다. 연구 2 에서는 개발한 척도의 신뢰도와 타당도를 검증하고자 한다.

[연구 1] 어머니 과보호 양육척도 문항 개발

\section{연구문제 1}

유아기 자녀를 둔 어머니의 과보호 양육척도 문항내용과 구 성요인은 어떠한가?

\section{Methods}

\section{연구대상}

서울시와 경기도에 거주하는 만 5,6세 유아기 자녀를 둔 어머 니 262명을 표집하였다. 연구 대상 선정을 위해 서울 및 경기 도 지역 내 맘카페(예: 상암동, 서대문구, 서초구, 판교)에 연구 에 참여할 어머니를 모집하는 글을 올린 뒤, 연구에 동의한 어 머니를 대상으로 온라인으로 설문을 진행하였다. 연구 대상의 수는 사례 수가 변수의 수보다 적어도 5 배 이상은 되어야 요인 분석 결과를 신뢰할 수 있다는 기준에 근거하였다(Tabachnick \& Fidell, 2013).

설문에 응답한 어머니의 평균 연령은 만 38 세 $(S D=3.10)$ 이 었다. 설문지 응답의 대상이 된 유아기 자녀의 평균 월령은 67 개월 $(S D=3.59)$ 이었으며 남아 140 명, 여아 122 명이었다.

연구에 참여한 어머니와 유아의 인구학적 특성을 간략히 살펴보면, 어머니의 학력은 대학교 졸업이 187 명 $(71.4 \%)$ 으 로 가장 많았고, 그 다음으로 대학원 이상 72 명(27.5\%), 고등 학교 졸업 3명 $(1.1 \%)$ 순이었다. 어머니의 취업 상태는 취업모 가 165 명(63.0\%)으로 가장 많았고, 그 다음으로 전업모 97명 (37.0\%) 순이었다. 유아의 형제 순위는 첫째가 158 명(60.3\%) 
으로 가장 많았고 그 다음으로 둘째 93 명 $(35.5 \%)$, 셋째 5명 (1.9\%), 무응답이 6명 $(2.3 \%)$ 순이었다. 가구 총 월수입은 800 만원 이상이 69명(26.3\%)으로 가장 많았고, 그 다음으로 600800 만원 67명(25.6\%), 500-600만원 43명(16.4\%), 400-500만 원 42명(16.0\%), 200-400만원 33명(12.6\%), 200만원 미만 7명 (2.7\%), 무응답 1 명 $(0.4 \%)$ 순이었다.

\section{연구도구}

\section{어머니 과보호 양육척도(유아용) 시안}

연구 1 에서는 다음의 세 과정을 거쳐 유아기 자녀를 둔 어머니 의 과보호 양육척도 시안을 구성하였다. 우선 과보호 양육에 대한 정의를 바탕으로 선행연구에서 주로 사용되었던 척도 문 항들을 추출하여 예비문항(67문항)을 구성하였다(I. J. Chung, 2012; Doh \& Falbo, 1999; Edwards et al., 2010; Parker, Tupling, \& Brown, 1979; Thomasgard et al., 1995; Wood, 2006). 다음으로 포 커스 그룹 인터뷰를 통해 유아기 자녀를 둔 어머니의 과보호 양육에 대한 인식을 조사하고 척도 예비문항의 적절성을 확인 하였다. 참가자는 연구 대상과 동일한 만 5, 6세 자녀를 둔 어 머니 10 명이었으며, 세 집단으로 나누어 인터뷰를 진행하였다. 마지막으로 예비문항에 대해 아동학 전공 교수, 유아교육기관 의 원장 및 원감, 아동학 박사로 구성된 7명의 전문가에게 내용 타당도를 검증받았다. 포커스 그룹 인터뷰와 내용타당도 분석 결과를 바탕으로 일부 문항을 삭제하고 세부 내용을 수정.보 완하여 과보호 양육척도 시안(45문항)을 구성하였다. 이에 대 한 구체적인 내용은 Y. S. Chung (2020)에서 확인할 수 있다.

본 연구에서 개발된 과보호 양육척도(유아용) 시안은 자기 보고식 질문지로 유아기 자녀를 둔 어머니의 과보호적인 양육 의 정도를 나타내는 45 개의 문항으로 구성되어 있다. 응답하 는 어머니는 각 문항과 관련된 자신의 양육태도에 대해 전혀 그렇지 않다(1점) 매우 그렇다(4점)의 4점 척도로 평정한다. 총점은 문항들의 평균 점수로 산출하였으며, 점수가 높을수록 어머니의 과보호 수준이 높다는 것을 의미한다.

\section{자료분석}

본 연구의 자료는 Mplus 8.3 (Muthén \& Muthén, 1998-2017) 과 SPSS 25.0 (IBM Co., Armonk, NY) 프로그램을 사용하여 기술통계분석, 탐색적 요인분석과 탐색적 구조방정식을 실 시하였다.

\section{Results}

\section{탐색적 요인분석}

과보호 양육척도 시안 45 문항에 대한 탐색적 요인분석을 실 시하였다. 먼저 요인분석에 이용된 변수들의 상관행렬이 요인 분석에 적합한지 확인하기 위하여, $\mathrm{KMO}$ 표본 적절성 수치와 Bartlett의 구형성 검증치를 알아보았다. 본 연구의 $\mathrm{KMO}$ 수치 는 .83 , Bartlett 검증치는 4634.35 ( $p<.001)$ 로 요인분석에 적 합한 자료라는 것을 확인하였다(Lee, 2002).

첫 번째로 공통성(communality)과 교차적재값을 점검하였 다. 각 변수들의 공통성이 적어도 .40이상이 되어야 한다는 기 준(Lee, 2002)에 따라.40미만인 13개 문항을 삭제하였다. 다 음으로 두 개 이상의 요인에서 요인적재치가 높은, 즉 교차적 재값이 .32이상인 문항을 삭제하였다(K. M. Chung \& Yoon, 2015; Reid, Roberts, Roberts, \& Piek, 2015). 이러한 기준에 따 라 문항 6 개가 삭제되었다.

두 번째로 문항 간의 상관을 초래하는 공통 요인을 추출하 기 위하여 26 개 문항에 대해 주축요인추출을 실시하였다. 요 인의 수를 결정하기 위하여 스크리 검정, 고유값, 누적분산비 율, 해석가능성을 고려하였다. 관련 수치들을 종합하여 살펴 보았을 때, 3 요인 구조와 4 요인 구조가 측정된 변량을 설명 하는데 가장 적합하다는 판단 아래 요인수를 3 개와 4 개로 지 정하여 각 요인 구조와 그에 해당하는 문항의 내용을 탐색하 였다. 그 결과, 요인의 수를 3 개로 지정했을 경우에 각 요인에 해당하는 문항의 내용이 개념적으로 구분이 가능하여 산출된 요인구조의 해석이 용이하였다. 따라서 본 연구에서 측정한 어머니 과보호 양육척도는 3 개의 하위요인으로 구분하였을 때, 가장 해석이 가능성이 높다고 볼 수 있다.

세 번째로 요인의 수를 3 개로 지정하여 공통요인분석을 다 시 실시하였다. 그 결과 요인행렬에서 각 요인과 관련이 높은 문항을 값이 큰 순서대로 10 개씩 확인하고, 어느 요인에서도 10 위 안에 들지 않는 5개 문항을 삭제하였다(Rhee \& Doh, 2014).

네 번째로 21 개 문항과 3 개 요인의 관계에 대한 해석을 위 해 탐색적 요인분석을 실시하였다. 각 요인 사이에 상관관계 가 있을 것으로 가정하여 Geomin방식으로 구조행렬을 산출하 였다. Geomin은 사각회전 방식으로 Thurstone의 단순구조를 잘 달성하는 상대적으로 최신의 방법이다(S. Kim, 2016). 그 결 과 1 요인에 11 개 문항, 2 요인에 4 개 문항, 3 요인에서는 6개 문항이 해당하였다. 1 요인 문항들 중에서 요인 부하량이 낮으 면서 모든 요인에서 유사한 수치를 보인 문항 1 개를 삭제하였 
Table 1

Exploratory Factor Analysis of Maternal Overprotection Scale for Young Children

\begin{tabular}{|c|c|c|c|c|}
\hline Sub scale & Item & \multicolumn{3}{|c|}{ Factor loading } \\
\hline \multirow[t]{8}{*}{ Intrusive control } & $\begin{array}{l}\text { I take care of my child because he/she is too young to do things for himself } \\
\text { (e.g., dressing, washing, and taking care of his/her own things). }\end{array}$ & .66 & & \\
\hline & I assist my child even if he/she can do it on his/her own. & .65 & & \\
\hline & When my child is putting on his/her clothes, I button up or zip them up for him/her. & .64 & & \\
\hline & I intervene in everything my child does. & .61 & & \\
\hline & I do things for my child which he/she does not want to do. & .61 & & \\
\hline & I tell my child to do things "this way" or "that way". & .60 & & \\
\hline & I pick out clothes for my child to wear for the day. & .49 & & \\
\hline & I like it when my child relies on me for any help. & .48 & & \\
\hline \multirow[t]{4}{*}{ Permissive indulgence } & I don't rebuke my child even if he/she acts rudely. & & .86 & \\
\hline & Even if my child interferes with other adults, I just let him/her do it. & & .82 & \\
\hline & I do not scold my child in front of others to protect my child to get hurt. & & .41 & \\
\hline & Even if he did wrong, when someone else scolds my child, I stand up for him/her. & & .36 & \\
\hline \multirow[t]{9}{*}{ Anxious protection } & When my child is out of my sight, I get worried that he/she will get hurt. & & & .82 \\
\hline & When my child is separated from me, I get worried that he/she will become anxious. & & & .69 \\
\hline & I protect my child so that he/she will not make any mistakes. & & & .55 \\
\hline & I let my child play indoor which is safer than outdoor. & & & .52 \\
\hline & I protect my child from experiencing frustration due to failures. & & & .47 \\
\hline & I try to meet my child's desires immediately. & & & .38 \\
\hline & Eigen value & 5.31 & 2.02 & 1.50 \\
\hline & $\%$ of variance & 29.49 & 11.24 & 8.31 \\
\hline & Cumulative \% & 29.49 & 40.73 & 49.04 \\
\hline
\end{tabular}

Note. $N=262$.

으며, 내용이 유사한 2 쌍의 문항들은 두 문항 중 한 개만 사용 하였다. 예를 들어, "아이의 장난감을 대신 치워준다." 문항은 “아이가 하기 싫어하는 일을 대신 해준다." 문항의 내용에 포 함되므로 후자의 문항을 선정하였다.

따라서 탐색적 요인분석 결과, 어머니 과보호 양육척도는 3 개의 요인 구조를 가진 18 개 문항으로 구성되었다. 본 연구에 서는 문항의 내용과 이론적 배경에 근거하여 요인 1 은 침해(8 문항), 요인 2는 응석/허용(4문항), 요인 3은 걱정/보호(6문항) 로 구분하였으며, 결과는 표 1 에 제시하였다.

\section{탐색적 구조방정식}

탐색적 요인분석을 통해 선정된 18 개 문항의 하위요인 구성 을 분석하기 위하여 탐색적 구조방정식을 실시하였다. 탐색적 구조방정식은 구조방정식, 확인적 요인분석, 탐색적 요인분석 의 통합적 측정모형으로 이전에 구성한 요인구조, 잠재변인간 의 관계를 확정해준다(Marsh, Morin, Parker, \& Kaur, 2014).
적합도 지수는 적합도와 간명성을 동시에 고려하는 RMSEA, CFI, TLI와 SRMR 지수를 이용하였다. 그 결과, $\chi^{2}$ 값은 $196.96(d f=99), \chi^{2} / d f$ 값은 $1.99, \mathrm{CFI}$ 는 $.93, \mathrm{TLI}$ 는 .90, $\mathrm{RMSEA}$ 는 .06 그리고 SRMR은 .04이었으며, $\chi^{2}$ 값은 $p<.001$ 수 준에서 유의하였다. 이러한 적합도 지수는 적절한 수준으로 연구 1 에서 개발한 어머니 과보호 양육척도의 18 개 문항으로 이루어진 3요인 모형의 적합도는 양호하다고 볼 수 있다.

\section{어머니 과보호 양육척도(유아용) 최종안}

본 연구에서는 최종적으로 18 개의 문항이 어머니 과보호 양 육척도에 포함되었다. 본 척도는 세 개의 하위요인으로 구 분되며, 침해(intrusive control) 8문항, 응석/허용(permissive indulgence) 4문항 그리고 걱정/보호(anxious protection) 6문항 으로 구성되었다. 침해는 유아가 자신의 일을 스스로 할 기회 를 제한하고 도와주고 개입하는 양육태도이며, 응석과 허용은 유아에게 행동 지도가 필요한 상황에서 훈육하지 않는 양육태 
도, 걱정과 보호는 유아가 부정적인 경험을 하지 않고 긍정적 인 경험만 하게 하려는 양육태도를 말한다.

[연구 2] 어머니 과보호 양육척도 타당화

\section{연구문제 1}

어머니 과보호 양육척도(유아용)의 신뢰도는 어떠한가?

\section{연구문제 2}

어머니 과보호 양육척도(유아용)의 타당도는 어떠한가?

\section{2-1. 어머니 과보호 양육척도(유아용)의 교차타당도는 어 떠한가?}

2-2. 어머니 과보호 양육척도(유아용)의 공인타당도는 어 떠한가?

\section{Methods}

\section{연구대상}

연구 1 에서 개발된 척도의 신뢰도와 타당도를 검증하기 위해 서울시와 경기도에 거주하는 만 5, 6세 유아의 어머니 197명 을 대상으로 설문 조사를 하였다. 연구대상 선정을 위해 어린 이집 12 곳과 유치원 5 곳을 섭외하여 재원 중인 만 5,6 세 유아 의 어머니에게 연구 설명문과 함께 연구 참여 동의서를 배부 하였다. 연구 참여에 동의한 경우에만 설문지를 배부하였으 며, 회수된 197 개 설문지를 분석에 활용하였다.

응답자의 평균 연령은 만 38세 $(S D=3.32)$ 이었으며, 설문 지 응답의 대상이 된 유아기 자녀의 평균 월령은 67 개월 $(S D=$ 3.56)이었으며 남아 94 명, 여아 102 명(무응답: 1명)이었다.

연구에 참여한 어머니와 유아의 인구학적 특성을 간략히 살펴보면, 어머니의 학력은 대학교 졸업이 147 명(74.6\%)으로 가장 많았고, 그 다음으로 대학원 이상 43 명 $(21.8 \%)$, 고등학교 졸업 6명 $(3.0 \%)$, 무응답 1 명 $(0.5 \%)$ 순이었다. 어머니의 취업 상태는 취업모가 123 명(62.4\%)으로 가장 많았고, 그 다음으로 전업모 72 명(36.5\%), 무응답 2명 $(1.0 \%)$ 순이었다. 유아의 형 제 순위는 첫째가 134 명(68.0\%)으로 가장 많았고 그 다음으로 둘째 53명(26.9\%), 셋째 9명(4.6\%), 무응답이 1 명 $(0.5 \%)$ 순이 었다. 가구 총 월수입은 800 만원 이상이 73 명 $(37.1 \%)$ 으로 가
장 많았고, 그 다음으로 600-800만원 44명(22.3\%), 500-600만 원 37명(18.8\%), 400-500만원 22명(11.2\%), 200-400만원 16명 (8.1\%), 무응답 4 명 $(2.0 \%), 200$ 만원 미만 1 명 $(0.5 \%)$ 순이었다.

\section{연구도구}

\section{어머니 과보호 양육척도(유아용)}

본 척도는 연구 1 을 통해 개발된 척도의 최종안으로 침해 8 문 항, 응석/허용 4문항 그리고 걱정/보호 6문항으로 구성되었다. 어머니는 자신의 양육행동을 바탕으로 각 문항에 대해 전혀 그렇지 않다(1점) 매우 그렇다(4점)의 4점 척도로 평정하였 다. 하위요인별 점수는 문항들의 평균 점수를 사용하였으며, 과보호 양육 총점은 하위요인별 점수를 합산하여 사용하였다.

\section{부모 양육행동 질문지}

어머니의 전반적인 양육행동을 조사하기 위해 Reid 등(2015) 이 개발한 부모 양육행동 및 차원 질문지(The Parenting Behaviours and Dimensions Questionnaire [PBDQ])를 번안 및 수정하여 사용하였다.

이 척도는 온정, 통제와 같은 전통적인 양육 차원과 함께 부 모의 훈육에서 나타나는 양육 특징을 포함하는 포괄적인 양육 척도로 개발되었다. 이를 위해 Parenting Scale (Arnold, O’Leary, Wolff, \& Acker, 1993)과 Parental Authority QuestionnaireRevised (Reitman, Rhode, Hupp, \& Altobello, 2002) 등과 같이 타당도가 검증되고 문헌에서 빈번하게 사용되는 척도에서 예 비 문항을 추출하고 재구성하여 척도를 개발하고 척도의 신 뢰도와 타당도를 검증하였다(Merz, Maskus, Melvin, $\mathrm{He}, \&$ Noble, 2019; Reid et al., 2015).

이 척도는 3 세에서 12 세 자녀를 둔 부모를 대상으로 한 자 기보고 질문지이며, 여섯 개의 하위요인으로 구분된다. 하위 요인은 애정과 정서적 지원을 보이는 양육태도인 정서적 온정 (emotional warmth), 가혹하고 기분에 따른 훈육 전략을 사용하 는 양육태도인 처벌적 훈육(punitive discipline), 유아를 어리게 여기고 안전과 행복에 대해 지나치게 염려하여 자율성과 독립 성을 저해하는 양육태도인 불안한 침해(anxious intrusiveness), 침해하고 과보호하는 것과 상반되는 것으로 반응적이고 적 절한 비계설정을 하는 양육태도인 자율성 지지(autonomy support), 유아의 행동이 다른 사람에게 피해를 주더라도 행동 적 자유를 많이 허용하고 비일관적인 양육태도인 허용적 훈육 
Table 2

Fit Index of Observed Model

\begin{tabular}{|c|c|c|c|c|c|}
\hline$\chi^{2}$ & $\chi^{2} / d f$ & CFI & TLI & RMSEA & SRMR \\
\hline $\begin{array}{l}191.28 \\
(d f=126, p=0.00)\end{array}$ & 1.52 & 0.92 & 0.90 & $\begin{array}{c}0.05 \\
.90 \text { C.I. }(0.03,0.06)\end{array}$ & 0.06 \\
\hline
\end{tabular}

(permissive discipline), 근거와 설명을 제시하며 훈육하는 양육 태도인 민주적 훈육(democratic discipline)으로 구성되어 있다. 하위요인별 내적합치도는 $.72, .83, .66, .72, .70, .73$ 이며, 문항 수는 각각 $6,5,6,5,6,5$ 개로 총 33 문항이다. 어머니는 자신의 양육행동과 각 문항의 내용이 일치하는 정도에 따라 전혀 그 렇지 않다(1점) 매우 그렇다(6점)의 6점 척도로 평정하며, 점 수는 하위요인별로 합산하여 분석에 사용하였다. 따라서 하위 요인별로 합산한 총점이 높을수록 해당하는 하위 차원의 양육 행동 경향성이 높다는 것을 의미한다.

\section{분석방법}

본 연구의 자료는 Mplus 8.3 (Muthén \& Muthén, 1998-2017)과 SPSS 25.0 (IBM Co., Armonk, NY) 프로그램을 사용하여 상관 관계 분석과 확인적 요인분석을 실행하였다.

\section{Results}

\section{내적 합치도}

어머니 과보호 양육척도의 신뢰도를 검증하기 위하여 문항들 이 구인을 측정하는데 얼마나 동질적인지 나타내는 문항의 내 적 합치도 계수, Cronbach's $\alpha$ 를 산출하였다. 그 결과, 문항 전 체의 내적 합치도 계수는 .85로 나타나 본 척도가 신뢰도 면에 서 양호한 도구라고 할 수 있다. 하위요인별로 살펴보면 침해 영역이 .82 , 응석/허용 영역이 .70, 걱정/보호 영역이 .75로 나 타났다.

\section{교차타당도}

연구 1 에서 검증된 척도의 요인구조가 연구 2 의 새로운 대상 에게 적용되는지 확인함으로써 교차타당도를 검증하였으며, 이를 위해 확인적 요인분석을 실시하였다. 분석에 앞서 자료 가 정규분포인지 확인하였다. 본 자료의 왜도는 $0.03 \sim 2.64$ 였
으며, 첨도는 $0.22 \sim 8.23$ 으로 산출되어 정규성 가정을 크게 위 배하지 않는 것으로 나타났다. 따라서 요인의 수를 탐색적 요 인분석에서 도출된 3 개로 지정하고 최대우도법을 반복하여 얻어진 카이제곱 통계량과 적합도 지수를 확인하였다.

표 2에 제시된 바와 같이 연구 2 모형의 적합도 지수는 적절 한 수준이었으며, 이로써 연구 1 에서 검증된 어머니 과보호 양 육척도의 18 개 문항으로 이루어진 3요인 모형이 새로운 대상 에게도 적합하다는 것이 확인되어 교차타당도가 검증되었다. 본 연구 모형의 그림을 그림 1 에 제시하였다.

\section{공인타당도}

공인타당도는 준거가 되는 척도와 개발한 척도의 점수 간 상 관관계를 통해 분석되며, 척도가 준거 행동을 얼마나 잘 설명 하는지 검토하는 것이다. 본 연구에서 PBDQ (Reid et al., 2015) 를 공인타당도용 척도로 사용한 이유는 자율성, 독립성, 의존 성과 같은 요소를 포함하고 있기 때문이다. 그리고 이 질문지 는 포괄적인 양육척도로 기존의 양육 차원을 포함하고 있어 본 연구의 과보호 양육척도로 측정된 어머니의 양육태도가 기 존의 양육 차원과 어떤 관계가 있는지를 살펴볼 수 있다.

척도의 조작적 정의에 기초하여 $\mathrm{PBDQ}$ 의 불안한 침해는 본 척도의 침해, 걱정/보호 하위요인과 상응하고, $\mathrm{PBDQ}$ 의 허 용적 훈육은 본 척도의 응석/허용 하위요인과 상응한다고 보 고 두 척도의 하위요인 간 상관관계를 분석하였다. 그 결과는 표 3에 제시하였다. 표 3에서 가설과 관계된 상관관계 수치는 음영으로 표시하였다. 그 결과, 음영으로 표시된 각 하위요인 간의 상관은 통계적으로 유의미한 수준으로 나타나 두 척도의 상응하는 하위요인들이 서로 관계가 있는 것을 측정한다고 볼 수 있으므로 공인타당도 측면에서 어머니 과보호 양육척도가 타당하다는 것이 검증되었다.

구체적으로 살펴보면, $\mathrm{PBDQ}$ 의 불안한 침해 점수와 과보 호 양육척도의 침해, 걱정/보호 점수 간의 상관관계는 각각 $.40, .66$ 으로 정적으로 유의하여 $(p<.001), \mathrm{PBDQ}$ 로 측정한 불 안한 침해 양육태도를 많이 하는 어머니는 침해하고 걱정하 여 보호하는 과보호 양육행동을 많이 보인다고 볼 수 있다. 또 
Table 3

Correlation Between the Parenting Behaviours and Dimensions Questionnaire and the Maternal Overprotection Scale

\begin{tabular}{lcccc}
\hline & & \multicolumn{2}{c}{ Maternal Overprotection Scale } \\
\hline PBDQ & Intrusive control & Permissive indulgence & Anxious protection & Total scores \\
Emotional warmth & .06 & & $.20^{*}$ & .05 \\
Punitive discipline & $.23^{* * *}$ & -.04 & .02 & .13 \\
Anxious intrusiveness & $.40^{* * *}$ & .04 & $.66^{* * *}$ & $.60^{* * *}$ \\
Autonomy support & $-.34^{* * *}$ & $-.23^{* *}$ & .06 & $.33^{* * *}$ \\
Permissive discipline & $.52^{* * *}$ & $.45^{* * *}$ & $.30^{* * *}$ & $.58^{* * *}$ \\
Democratic discipline & .04 & -.11 & .13 \\
\hline
\end{tabular}

Note. $N=197$.

${ }^{*} p<.05{ }^{* *} p<.01{ }^{* * *} p<.001$.

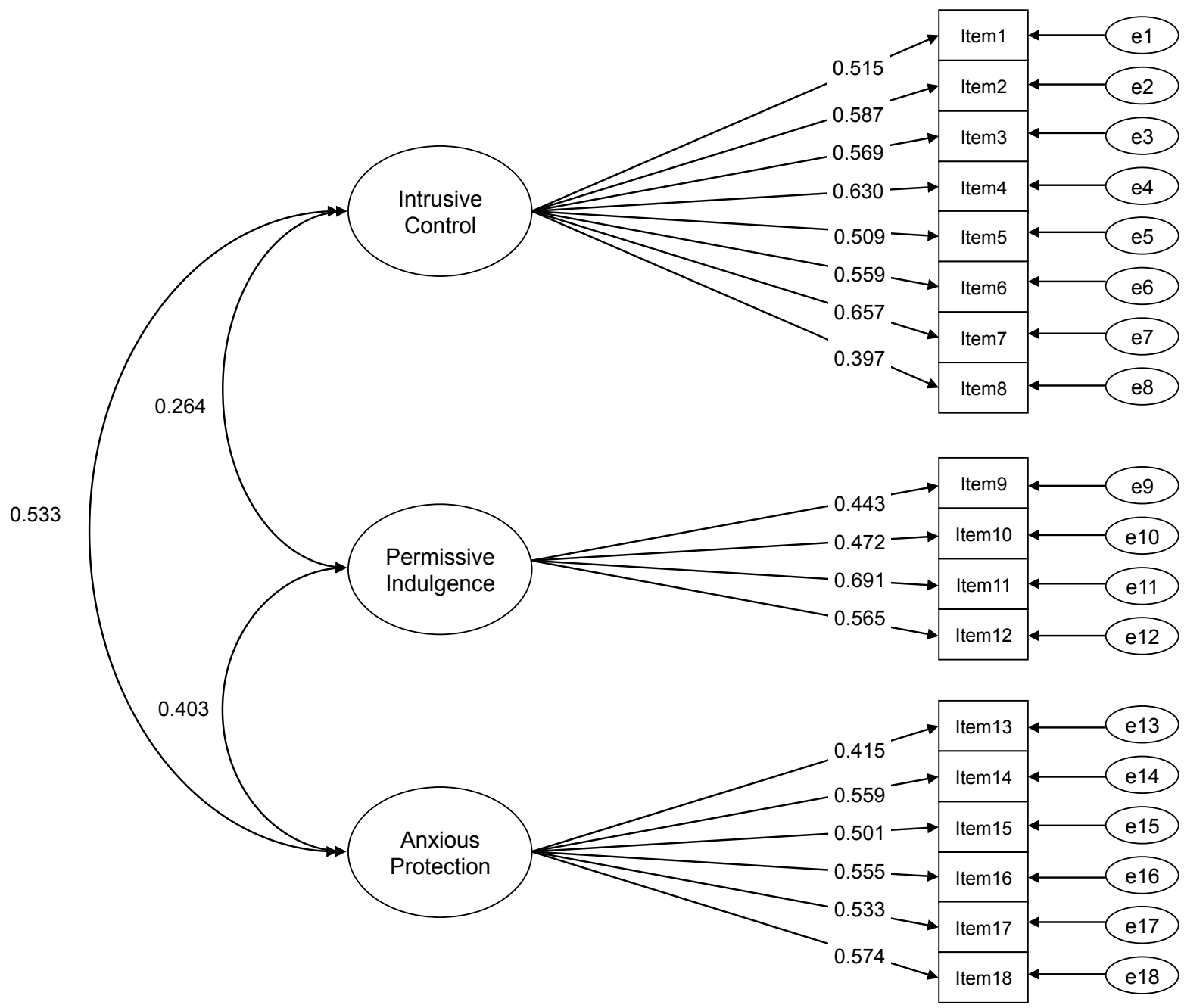

Figure 1. Model of factor structure.

한 $\mathrm{PBDQ}$ 의 허용적 훈육과 과보호 양육척도의 응석/허용 점 수 간의 상관관계도 정적으로 유의하였으며 $(r=.45, p<.001)$, 이는 $\mathrm{PBDQ}$ 로 측정한 허용적 훈육을 많이 하는 어머니는 허
용적이고 응석을 받아주는 과보호 양육행동을 많이 보인다고 볼 수 있다. 마지막으로 과보호 양육 총점과 $\mathrm{PBDQ}$ 의 불안한 침해와 허용적 훈육 간의 관계는 $.60, .58$ 로 정적으로 유의하 
였으며 $(p<.001)$, 자율성 지지와는 부적인 상관관계 $(r=-.28$, $p<.001)$ 가 발견되었다. 이러한 결과는 본 척도의 총점을 바탕 으로 과보호 양육행동을 많이 하는 어머니는 불안하여 자녀의 일상을 침해하는 행동과 허용적 훈육을 동시에 많이 보이며, 자율성을 지지하는 양육행동은 적게 한다고 해석할 수 있다.

\section{Discussion}

본 연구에서는 과보호 양육을 유아가 부정적 경험을 하는 것을 걱정하고 보호하여 발달에 적합하지 않게 통제하고 허용하는 양육태도로 정의하고, 유아기 자녀를 둔 어머니의 과보호적인 양육의 정도를 측정할 수 있는 도구를 개발, 타당화하였다.

연구 1 에서 개발된 어머니 과보호 양육척도(유아용)는 18 개 문항과 침해, 응석/허용, 걱정/보호의 3개 하위요인으로 구성되 었다. 3 개 하위요인에 대한 개념과 특징을 구체적으로 살펴보 면, 첫 번째 과보호 양육의 침해적 요인은 유아가 자신의 일을 발달에 맞게 스스로 할 기회를 제한하고 도와주고 개입하는 양 육태도를 말한다. 여기서 유아가 스스로 할 수 있는 자신의 일 이란 옷을 입거나 씻는 것 등의 일상생활의 자조 기술과 관련 된 것으로 이에 대한 부모의 침해적 행동은 유아의 자율성과 유 능감을 저해할 수 있다(Eisenberg, Taylor, Widaman, \& Spinard, 2015; L. Kim, 2017). 두 번째 요인인 과보호 양육의 응석/허용 요인은 유아에게 행동 지도가 필요한 상황에서 훈육하지 않는 양육태도이다. 허용적 과보호를 하는 부모는 자녀를 과대평가 하여 자녀의 결점을 바로 볼 줄 모르고 타인의 충고와 비난을 받아들일 줄 모르는 모습을 보일 수 있다(Park, 1998). 세 번째 요인인 과보호 양육의 걱정/보호 요인은 유아가 부정적인 경험 을 하지 않고 긍정적인 경험만 하게 하려는 양육태도를 말한다. 과보호하는 부모는 유아에게 스트레스가 될 수 있는 근원을 미 리 제거하거나 방패막이(shield)를 해주고자 외부 영향에 대해 보호하는 모습을 보인다(Kiel \& Buss, 2011; Parker, 1983).

연구 2에서는 어머니 과보호 양육척도(유아용)의 신뢰도와 타당도를 확인하고자 내적 합치도, 교차타당도, 공인타당도를 분석하였다. 그에 대해 구체적으로 논의하면 첫째, 본 척도의 내적 합치도와 교차타당도는 양호한 수준으로 나타났다. 교차 타당도를 검증하기 위해 연구 1 과는 다른 표본 집단을 대상으 로 확인적 요인분석을 실시하였고 그 결과 다른 표본에서 요 인구조의 안정성과 적합성을 확인하였다.

둘째, 개발한 어머니 과보호 양육척도의 공인타당도를 검 증하기 위하여 $\mathrm{PBDQ}$ 로 측정한 어머니 양육행동과 상관관계
를 살펴보았다. 연구 2 결과에서 제시한 가설에 맞게 두 척도 의 하위요인간 상관관계에 관한 척도 간 상응하는 하위요인인 불안한 침해와 과보호 양육의 침해와 걱정/보호, 그리고 허용 적 훈육과 과보호 양육의 응석/허용 하위요인 간에 유의한 상 관관계가 발견되었다. 또한 자율성을 지지하는 양육태도는 본 척도로 측정된 과보호 양육 총점과 부적으로 유의한 관계가 있었다. 이러한 결과를 통해 어머니 과보호 양육척도가 과보 호 양육의 구성 개념인 침해, 응석/허용, 걱정/보호에 해당하 는 양육 태도를 타당하게 측정하며, 자율성을 저해하는 과보 호 양육의 특징을 잘 보여준다는 것을 알 수 있다.

과보호 양육의 하위요인별로 살펴보았을 때, 과보호 양육의 걱정/보호 요인은 불안한 침해 양육행동 외에 허용적, 민주적 훈육, 정서적 온정과 정적인 관계가 있었다. 이 결과는 $\mathrm{PBDQ}$ 개발 연구(Reid et al., 2015)에서 걱정하고 침해하는 양육이 허 용적, 민주적 훈육, 정서적 온정과 강한 정적 관계가 나타난 것 과 유사하다. 이러한 관계는 걱정하고 보호하는 과보호를 하 는 어머니는 온정적이고 민주적인 긍정적 양육태도를 가지고 있거나 긍정적인 양육태도를 지향한다고 해석할 수 있다. 전자 의 해석은 유아의 부정적 정서에 대한 어머니의 예민한 반응은 긍정적, 부정적 양육행동과 모두 관련이 있다는 선행연구와 일 치하는 결과이며(Oh, 2013), 어머니의 과보호 양육이 온정, 민 감성과 같은 긍정적인 양육 요인을 함께 포함하고 있다는 연구 자들의 주장을 뒷받침한다(LeMoyne \& Buchanan, 2011). 이러 한 과보호 양육의 양면성은 자녀에게 높은 관심을 가지고 관여 하는 양육의 적절한 수준이 어디인지 그리고 적절한 수준이 연 령, 기질, 성별과 같은 자녀의 특성에 따라 어떠한지에 대한 탐 색이 추후 연구를 통해 필요하다는 것을 보여준다.

후자의 해석은 사회적 바람직성에 의한 응답 경향과 관계 가 있다. 다시 말해서 유아의 건강과 행복을 중요하게 여겨 외 부로부터 받을 수 있는 위험과 상처를 걱정하고 미리 보호하 는 어머니일수록 긍정적인 양육태도를 지향하기 때문에 두 양 육행동 간에 유의한 정적 상관관계가 나타났을 가능성이 있 다. 중국과 미국을 비롯한 9개 국가에서 양육과 관련된 어머 니와 아버지의 사회적 바람직성 응답에 대해 살펴본 결과, 자 기보고에 근거한 긍정적인 양육태도 간에 유의한 상관관계가 있었으며, 바람직성 응답 경향은 집단의 규범을 중요시하는 아시아 문화인 중국에서 가장 높게 나타났다(Bornstein et al., 2015). 바람직성 응답은 어머니의 양육태도를 자기보고식 질 문지로 측정하는 방법의 한계일 수 있으며, 이에 대한 구체적 인 논의는 연구의 제한점과 관련하여 다루었다.

본 연구의 제한점 및 후속연구를 위한 제언은 다음과 같다. 
첫째, 척도 형식에 따른 측정의 제한점이 있다. 본 연구의 어머 니 과보호 양육척도는 자신의 양육태도를 스스로 평정하는 자 기보고식 질문지의 형태로 개발되었기 때문에, 응답자가 바람 직성에 의해 평정을 하여 실제 행동과 차이가 있을 수 있는 단 점이 있다. 따라서 본 연구에서 개발한 과보호 양육 질문지가 측정의 타당성을 가지려면, 실제 양육하는 모습과의 관련성을 밝히는 것이 필요하다. 그를 위해 추후 연구에서는 부모의 양 육행동을 직접 관찰하여 평정한 과보호 양육과 본 척도로 측 정한 과보호 양육을 서로 비교해볼 수 있다.

둘째, 표집에 따른 연구결과 일반화와 관련된 제한점이 있 다. 과보호 양육현상은 가족의 사회경제적 지위에 따라 발 생 빈도와 그에 따른 영향이 다르게 나타난다고 알려져 있다 (Shaffer, 2009). 본 연구 대상의 가구 총 월수입을 살펴보았을 때 월 600만원 이상인 경우가 과반수를 차지한다. 이는 2019년 1 분기 기준, 2 인 이상 가구의 월수입인 평균 약 483 만원보다 높 은 수준이며, 소득구간을 5 분위로 나누었을 때, 4 분위(약 586 만 985만)에 해당하는 수준이다(Statistics Korea, 2019b). 따라 서 본 연구의 결과를 해석하고 적용할 때, 표집대상이 모집단 보다 가구소득이 높다는 특징을 고려해야 한다. 그러나 과보 호 양육이 중산층 이상의 가정에서 더 많이 발생하고 그에 따 른 영향도 저소득층과 비교했을 때 부정적일 수 있기 때문에 (Bernstein \& Triger, 2010; I. J. Chung, 2012) 이러한 본 연구대상 의 특성이 과보호 양육을 연구하기에 적합할 수 있다. 하지만 가정의 사회경제적 지위와 과보호 양육 간에 관계가 없다는 상 반된 결과도 있다(Ganon, 2019). 본 연구에서도 어머니의 교육 수준 $(F=.557, p=.574)$ 및 가구 총 월수입 $(F=.464, p=.803)$ 에 따른 과보호 양육 수준에 유의한 차이가 발견되지 않았다. 따 라서 추후 연구에서는 다양한 인구학적 특성을 가진 집단을 대 상으로 과보호 양육현상을 연구할 필요가 있다.

위와 같은 제한점에도 불구하고 본 연구는 다음과 같은 시 사점과 함의를 갖는다. 첫째, 학문적으로 합의가 부족한 유아 기 과보호 양육에 대한 정의를 확립하고, 그에 따른 척도를 개 발하여 유아기 자녀를 둔 어머니 과보호 양육의 초기 영향에 대해 살펴볼 수 있는 수단을 마련하였다. 과보호 양육의 기존 연구 및 측정 도구들은 청소년 및 성인초기 자녀를 대상으로 이루어졌다(E. Y. Chung \& Chang, 2008; K. M. Chung \& Yoon, 2015; J. Y. Kim \& Oh, 2011). 하지만 자녀의 일상에 개입하고 자율성을 제한하는 부모의 과보호 양육은 어린 시절부터 나타 나며, 부모는 이러한 태도를 이후에도 지속하는 경향이 있기 때문에(LeMoyne \& Buchanan, 2011; Park, 1998), 상대적으로 변화가능성이 높은 양육의 초기에 나타나는 과보호 양육에 대
한 연구를 할 필요가 있다. 특히 과보호 양육은 유아의 자율성 을 저해하는 양육태도임에도 불구하고 어려움에 대처하는 반 응, 숙달 및 성취동기, 유능감과 같은 자율성과 관련된 유아의 특성과의 관계는 아직 밝혀지지 않아 이러한 관계는 추후 연 구에서 다루어져야 할 부분이다. 본 연구에서 개발한 어머니 과보호 양육척도(유아용)를 통해 그동안 연구가 되지 않았던 과보호 양육의 초기 영향을 밝혀 자율성과 주도성을 기르는 유아기에 바람직한 양육방법을 구체적으로 제시할 수 있다.

둘째, 본 척도는 침해, 응석/허용, 걱정/보호의 하위요인으 로 구분되어 과보호 양육의 다차원적 특성을 반영하였다. 유아 와 관련된 기존의 과보호 양육척도 중 하위요인이 구분된 것 은 부모 보호 척도([PPS], Thomasgard et al., 1995)뿐이며, 과보 호 양육 개념에 대한 연구자의 주장과 달리 과보호 양육의 허 용적 측면은 측정에 포함되지 않았고 하위 영역 중 의존성과 통제는 개념 및 문항 내용에서 명확히 구분되지 않는 제한점이 있다. 특히, 과보호 양육의 허용적 측면은 한국에서 더 강조되 는 특성으로 문화 특수성을 반영한 척도를 구성하기 위해서 포 함되어야 할 하위요인이다. 또한 통제적 과보호 양육과 허용적 과보호 양육이 야기하는 발달적 결과가 다를 수 있으므로, 하 위요인을 구분하여 과보호 양육을 측정하지 않을 경우 효과가 상충되어 결과가 왜곡될 수 있다. 본 척도는 과보호 양육의 허 용적 측면을 포함하여 과보호 양육 정의에 대한 한국의 문화적 맥락을 반영하였으며, 하위요인으로 구분함으로써 과보호 양 육이 유아에게 미치는 영향이 하위요인에 따라 어떠한지를 구 체적으로 밝힐 수 있도록 하였다는데 의의가 있다.

\section{Notes}

This article is a part of the first author's doctoral dissertation submitted in 2020, and was presented at the 2019 Annual Fall Conference of the Korean Association of Child Studies.

\section{Conflict of Interest}

No potential conflict of interest relevant to this article was reported.

\section{Ethics Statement}

All procedures of this research were reviewed by IRB (7001988202003-HR-513-06). 


\section{References}

\section{In English}

Arnold, D. S., O’Leary, S. G., Wolff, L. S., \& Acker, M. M. (1993). The parenting scale: A measure of dysfunctional parenting in discipline situations. Psychological Assessment, 5(2), $137-$ 144. doi:10.1037/1040-3590.5.2.137

Bayer, J. K., Sanson, A. V., \& Hemphill, S. A. (2006). Parent influences on early childhood internalizing difficulties. Journal of Applied Developmental Psychology, 27(6), 542559. doi:10.1016/j.appdev.2006.08.002

Bernstein, G. \& Triger, Z. (2011). Over-parenting. UC Davis Law Review, 44(4), 1221-1279.

Bornstein, M. H., Putnick, D. L., Lansford, J. E., Pastorelli, C., Skinner, A. T., Sorbring, E.,...Oburu, P. (2015). Mother and father socially desirable responding in nine countries: Two kinds of agreement and relations to parenting selfreports. International Journal of Psychology, 50(3), 174-185. doi:10.1002/ijop.12084

Doh, H. S., \& Falbo, T. (1999). Social competence, maternal attentiveness, and overprotectiveness: Only children in Korea. International Journal of Behavioral Development, 23(1), 149-162. doi:10.1080/016502599384044

Edwards, S. L., Rapee, R. M., \& Kennedy, S. (2010). Prediction of anxiety symptoms in preschool-aged children: Examination of maternal and paternal perspectives. Journal of Child Psychology and Psychiatry, 51(3), 313-321. doi:10.1111/ j.1469-7610.2009.02160.x

Eisenberg, N., Taylor, Z. E., Widaman, K. F., \& Spinrad, T. L. (2015). Externalizing symptoms, effortful control, and intrusive parenting: A test of bidirectional longitudinal relations during early childhood. Development and Psychopathology, 27(4), 953-968. doi:10.1017/S0954579415000620

Ganon, R. J. (2019). Examining overparenting, socioeconomic status, and parental out-of-school time experience: Does socioeconomic status and out-of-school-time experience matter? Children and Youth Services Review, 101(1), 181189. doi:10.1016/j.childyouth.2019.04.003

Kiel, E. J., \& Buss, K. A. (2011). Prospective relations among fearful temperament, protective parenting, and social withdrawal: The role of maternal accuracy in a moderated mediation framework. Journal of Abnormal Child Psychology, 39(7), 953-966. doi:10.1007/s10802-011-9516-4

Kiel, E. J., Premo, J. E., \& Buss, K. A. (2016). Maternal encouragement to approach novelty: A curvilinear relation to change in anxiety for inhibited toddlers. Journal of Abnormal Child Psychology, 44(3), 433-444. doi:10.1007/ s10802-015-0038-3
Kiel, E. J., Wagers, K. B., \& Luebbe, A. M. (2019). The attitudes about parenting strategies for anxiety scale: A measure of parenting attitudes about protective and intrusive behavior. Assessment, 26(8), 1504-1523. doi:10.1177/1073191117719513

Kim, Y. H., \& Cohen, D. (2010). Information, perspective, and judgments about the self in face and dignity cultures. Personality and Social Psychology Bulletin, 36(4), 537-550. doi:10.1177/0146167210362398

Laurin, J. C., Joussemet, M., Tremblay, R. E., \& Boivin, M. (2015). Early forms of controlling parenting and the development of childhood anxiety. Journal of Child and Family Studies, 24(11), 3279-3292. doi:10.1007/s10826-015-0131-9

LeMoyne, T., \& Buchanan. T. (2011). Does "hovering" matter? Helicopter parenting and its effect on well-being. Sociological Spectrum, 31(4), 399-418. doi:10.1080/027321 73.2011 .574038

Levy, D. M. (1966). Maternal overprotection. New York: Norton.

Marsh, H. W., Morin, A. J. S., Parker, P. D., \& Kaur, G. (2014). Exploratory structural equation modeling: An integration of the best features of exploratory and confirmatory factor analysis. Annual Review of Clinical Psychology, 10(1), 85110. doi:10.1146/annurev-clinpsy-032813-153700

McShane, K. E., \& Hastings, P. D. (2009). The new friends vignettes: Measuring parental psychological control that confers risk for anxious adjustment in preschoolers. International Journal of Behavioral Development, 33(6), 481495. doi:10.1177/0165025409103874

Merz, E. C., Maskus, E. A., Melvin, S. A., He, X., \& Noble, K. G. (2019). Parental punitive discipline and children's depressive symptoms: Associations with striatal volume. Developmental Psychobiology, 61(6), 953-961. doi:10.1002/ dev.21859

Mplus (Version 8.3). [Computer software]. Los Angeles, CA: Muthén \& Muthén.

Parker, G. (1983). Parental overprotection: A risk factor in psychosocial development. New York: Grune \& Stratton.

Parker, G., Tupling, H., \& Brown, L. B. (1979). A Parental Bonding Instrument. British Journal of Medical Psychology, 52(1), 1-10. doi:10.1111/j.2044-8341.1979.tb02487.x

Reid, C. A. Y., Roberts, L. D., Roberts, C. M., \& Piek, J. P. (2015) Towards a model of contemporary parenting: The parenting behaviours and dimensions questionnaire. PLOS ONE, 10(6), 1-23. doi:10.1371/journal.pone.0114179

Reitman, D., Rhode, P. C., Hupp, S. D. A., \& Altobello, C. (2002). Development and validation of the parental authority questionnaire-revised. Journal of Psychopathology and Behavioral Assessment, 24(2), 119-127. doi:10.1023/ A: 1015344909518

Shaffer, D. R. (2009). Social and personality development (6th ed.). Belmont, CA: Wadsworth. 
Tabachnick, B. G., \& Fidell, L. S. (2013). Using multivariate statistics (6th ed.). London: Pearson Education.

Thomasgard, M., \& Metz, W. P. (1993). Parental overprotection revisited. Child Psychiatry and Human Development, 24(2), 67-80. doi:10.1007/BF02367260

Thomasgard, M., Metz, W. P., Edelbrock, C., \& Shonkoff, J. P. (1995). Parent-child relationship disorder. Part I. Parental overprotection and the development of the Parent Protection Scale. Journal of Developmental and Behavioral Pediatrics, 16(4), 244-250.

Wood, J. J. (2006). Parental intrusiveness and children's separation anxiety in a clinical sample. Child Psychiatry and Human Development, 37(1), 73-87. doi:10.1007/s10578-0060021-x

Wood, J. J., Kiff, C., Jacobs, J., Ifekwunigwe, M., \& Piacentini, J. C. (2007). Dependency on elementary school caregivers: The role of parental intrusiveness and children's separation anxiety. Psychology in the School, 44(8), 823-837. doi:10.1002/pits.20268

\section{In Korean}

Chung, E. Y., \& Chang, S. S. (2008). The development of an overprotection scale based on teenagers' perception of their mothers. The Korean Journal of Counseling and Psychotherapy, 20(2), 293-312.

Chung, I. J. (2012). The influences of parental neglect, overprotection and private tutoring on development in early childhood. The Korean Journal of Early Childhood Education, 32(4), 255-278. doi:10.18023/kjece.2012.32.4.012

Chung, K. M., \& Yoon, S. Y. (2015). Development and validation of the Korean-parental overprotection scale: For high school students. The Korean Journal of School Psychology, 12(1), 1-29. doi:10.16983/kjsp.2015.12.1.1

Chung, Y. S. (2020). The development and validation of a maternal overprotection scale for young children (Doctoral dissertation). Retrieved from http://www.riss.kr/link?id= T15526318

Jang, Y. J. (2016). The effects of mothers' anxiety psychological control parenting and attention to achievement on children's responses to a task rechallenge: The mediating effects of self-efficacy (Doctoral dissertation). Retrieved from http://www.riss.kr/ link?id=T14068271

Kim, J. Y., \& Oh, K. J. (2011). The effect of parental overprotection on depression: The mediation effect of ego-resilience according to the gender. Korean Journal of Clinical Psychology, 30(3), 647-661. doi:10.15842/kjcp.2011.30.3.002

Kim, L. (2017). Effects of maternal intrusive parenting on mastery motivation in children: Focusing on the moderation role of children's temperament (Doctoral dissertation). Retrieved from http://www.riss.kr/link?id=T14595593

Kim, S. (2016). Fundamentals and extensions of structural equation modeling: With MPLUS examples. Seoul: Hakjisa.

Lee, Y. (2002). Yo-in-bun-seog-ui i-hae [요인분석의 이해]. Seoul: Seokjeong.

Oh, J. H. (2013). The development and validity of a scale for measuring mother's reaction to children's negative emotion. Korean Journal of Child Studies, 34(6), 97-122. doi:10.5723/ KJCS.2013.34.6.97

Park, A.-C. (1998). A note on the over-protection for childrearing in its developmental psychological aspects. The Korean Journal of the Human Development, 5(1), 53-72.

Rhee, S. H., \& Doh, H. S. (2014). The development and validation of a parenting behavior scale for parents of early school-age children. Korean Journal of Child Studies, 35(6), 111-133. doi:10.5723/KJCS.2014.35.6.111

Statistics Korea. (2019a). Ja-nyeo-su-byeol ga-gu_si-gun-gu [자녀수 별 가구_시군구]. Retrieved February 6, 2021, from kosis. $\mathrm{kr} /$ statHtml/statHtml.do?orgId=101\&tblId=DT_1BC160 $1 \&$ conn_path=I2

Statistics Korea. (2019b). So-deug-5-bun-wi-byeol ga-gu-dang gagye-su-ji [소득 5분위별 가구당 가계수지]. Retrieved November 21, 2019, from kosis.kr/statHtml/statHtml.do? $\operatorname{orgId}=101 \&$ tblId=DT_1L9H006\&conn_path

\section{ORCID}

Young Sun Chung http://orcid.org/0000-0001-9360-4927 Kyung Ja Park http://orcid.org/0000-0003-2865-0788

Received February 25, 2021

Revision received April 23, 2021 Accepted May 31, 2021 